\title{
Ezrin promotes invasion and metastasis of pancreatic cancer cells
}

\author{
Yunxiao Meng, Zhaohui Lu, Shuangni Yu, Qiang Zhang, Yihui Ma, Jie Chen*
}

\begin{abstract}
Background: Pancreatic cancer has a high mortality rate because it is usually diagnosed when metastasis have already occurred (microscopic and gross disease). Ezrin plays important roles in cell motility, invasion and tumor progression, and it is especially crucial for metastasis. However, its function in pancreatic cancer remains elusive.

Methods and Results: We found that ezrin overexpression promoted cell protrusion, microvillus formation, anchorage-independent growth, motility and invasion in a pancreatic cancer cell line, MiaPaCa-2, whereas ezrin silencing resulted in the opposite effects. Ezrin overexpression also increased the number of metastatic foci (6/8 vs. $1 / 8$ ) in a spontaneous metastasis nude mouse model. Furthermore, ezrin overexpression activated Erk1/2 in MiaPaCa-2 cells, which might be partially related to the alteration of cell morphology and invasion. Immunohistochemical analysis showed that ezrin was overexpressed in pancreatic ductal adenocarcinoma (PDAC) (91.4\%) and precancerous lesions, i.e. the tubular complexes in chronic pancreatitis (CP) and pancreatic intraepithelial neoplasm (PanIN) (85.7\% and 97.1\%, respectively), compared to normal pancreatic tissues (0\%). Ezrin was also expressed in intercalated ducts adjacent to the adenocarcinoma, which has been considered to be the origin of ducts and acini, as well as the starting point of pancreatic ductal carcinoma development.

Conclusions: We propose that ezrin might play functional roles in modulating morphology, growth, motility and invasion of pancreatic cancer cells, and that the Erk1/2 pathway may be involved in these roles. Moreover, ezrin may participate in the early events of PDAC development and may promote its progression to the advanced stage.
\end{abstract}

\section{Background}

Ezrin, encoded by the Vil2 gene, is a member of the ERM family; it provides a functional link between the plasma membrane and the cortical actin cytoskeleton of the cell. Ezrin plays important roles in cell motility, morphogenesis, adhesion, survival and apoptosis [1-6]. It also participates in crucial signal transduction pathways [7]. Ezrin binds to cell surface glycoproteins, such as CD43, CD44, ICAM-1 and ICAM-2, through interacting with their amino $(\mathrm{N})$-terminal domains. Ezrin also binds to filamentous actin through its carboxyl (C)-terminal domains [8]. Ezrin has been linked to molecules that control the phosphatidylinositol-3-kinase, AKT, Erk1/2 MAPK and Rho pathways, which are functionally involved in signaling events regulating cell survival, proliferation and migration. Phosphorylation of ezrin

\footnotetext{
* Correspondence: xhblk@163.com

Department of Pathology, Peking Union Medical College Hospital, Chinese Academy of Medical Sciences and Peking Union Medical College, Tsinghua University, 1 Shuai Fu Yuan Hu Tong, Beijing, China
}

induces its translocation from the cytoplasm to the plasma membranes of microvillus and confers the ability of binding to plasma membrane and actin filaments [9-12].

Ezrin is expressed in a variety of normal and neoplastic cells, including many types of epithelial, lymphoid and glial cells $[5,13,14]$. In melanoma cells, ezrin has been shown to be localized in phagocytic vacuoles, suggesting that its association with the actin cytoskeleton is crucial for the phagocytic activity [15]. Phagocytic behavior is usually considered to be an indicator of highgrade malignancy in melanomas. In addition, immunohistochemical analysis has demonstrated a significant correlation between increased ezrin immunoreactivity and a high histological grade in astrocytoma [16]. In a complementary DNA (cDNA) microarray analysis of highly and poorly metastatic rhabdomyosarcomas, ezrin was indicated to be a key regulator of metastasis [17]. Ezrin overexpression has also been considered as an independent predictor of adverse outcome of 
gastrointestinal stromal tumors [18]. These results indicated that ezrin expression level is closely associated with malignant progression of cancer.

Consistent with these reports, suppression of ezrin protein expression and disruption of its function significantly reduced lung metastasis in a mouse osteosarcoma model [19]. Furthermore, high-level ezrin expression in canine osteosarcomas has been associated with early development of metastasis [20]. Ezrin silencing by small hairpin RNA could reverse the metastatic behavior of human breast cancer cells [21]. Taken together, the observed effects of ezrin overexpression and silencing on the cell malignant transformation indicate a role for ezrin in regulating tumor metastasis and progression [22].

In pancreatic carcinomas, a high-level ezrin expression is associated with high metastatic potential; membrane translocation of ezrin might play a role in the progression from borderline tumor to malignant transformation. Patients with pancreatic ductal adenocarcinoma (PDAC) with membranous ezrin expression exhibited poorer prognosis compared to those without membranous ezrin expression, and ERM protein was more likely to be present in poorly differentiated cancers [23-26]. A recent study showed that overexpression of pEzrin (Tyr353) in pancreatic cancers was associated with positive lymph node metastasis, less differentiation, pAkt overexpression and shorter survival times [27]. Ezrin can interact with cortactin to form podosomal rosettes in pancreatic cancer cells, thereby playing a role in pancreatic cancer invasion [28]. However, the mechanisms of ezrin-mediated tumor development still require further elucidation. In this study, we investigated the effect of ezrin on the motility and invasion ability of the pancreatic cancer cell line MiaPaCa-2, as well as the expression of ezrin in pancreatic duct adenocarcinoma, chronic pancreatitis and normal pancreatic tissues.

\section{Materials and methods}

\section{Antibodies and plasmids}

Rabbit polyclonal anti-ezrin antibody was purchased from Upstate technology (Lake Placid, NY). Rabbit polyclonal anti-phosphorylated Ezrin (Tyr353), mouse monoclonal anti-AKT, anti-phospho-AKT (Ser473), anti-p44/42 MAPK (Erk1/2) and anti-phospho-p44/42 MAPK (Erk1/2) (Thr202/Tyr204) antibodies were purchased from Cell Signaling Technology (Beverly, MA, USA). The mouse monoclonal antibody VSV-G (P5D4) was purchased from Roche Applied Science (Indianapolis, USA). The mouse monoclonal antibody GAPDH was purchased from Santa Cruz Biotechnology (Santa Cruz, CA). The secondary antibodies, including the rhodamine-conjugated goat anti-mouse, FITC-conjugated goat anti-mouse, horseradish peroxidase-conjugated antimouse and anti-rabbit antibodies, were purchased from
ZhongShan Biotechnology (Beijing, China). The pcb6 vector that contains the cDNA encoding VSV-G-tagged ezrin was kindly provided by Dr. Monique Arpin [14].

\section{Plasmid-based silencing of ezrin expression}

The mammalian expression vector, pSilencer 2.1-U6 (Ambion, Austin, Texas, USA) was used for expressing of siRNA in MiaPaCa-2 cells. Briefly, two primer pairs were synthesized, with the first pair encoding the nucleotides, GGGCCAAGTTCTACCCTGAAG (376396, No. 1) followed by a 9 base "loop", TTCAAGAGA and an inverted repeat and the second pair encoding the nucleotides, GGCTTTCCTTGGAGTGAAA (849-867, No. 2) followed by the loop and the inverted repeat. A nonspecific 21-nucleotide siRNA scrambled to the first pair, GACCGAGTCCGAAGTCAGCT (No. 3) was used as a control. The primer pairs were annealed and inserted into the BamH I and Hind III sites of pSilencer 2.1-U6 and transformed into JM109 competent cells (Promega, Madison, WI, USA). Positive clones were identified and verified by restriction enzyme analysis and sequence analysis.

\section{Cell culture and cell transfection}

The pancreatic adenocarcinoma cell line MiaPaCa-2 (American Type Culture Collection, Manassas, Virginia, USA) was grown in DMEM (GIBCO, Grand Island, New Yolk, USA) supplemented with $10 \%$ fetal calf serum (FCS) and 1\% L-glutamine (Invitrogen, Karlsruhe, Germany) and maintained at $37^{\circ} \mathrm{C}$ in $5 \% \mathrm{CO}_{2}$. All transfections reactions were performed using Lipofectamine 2000 (Invitrogen; Carlsbad, CA) in accordance with the manufacturer's instructions. Stable transfectants were selected with $800 \mu \mathrm{g} / \mathrm{mL}$ G418 (Sigma-Aldrich, St. Louis, MO, USA), and individual clones were isolated.

\section{Scanning electron microscopy}

Cells were cultured on coverslips and harvested after 24 hours. Cells were then washed with phosphate buffered saline (PBS) and fixed with $2.5 \%$ glutaraldehyde at $4^{\circ} \mathrm{C}$ for 12 hours. After thoroughly washing with PBS, the fixed cells were dehydrated through an ethanol series and dried at room temperature. The samples were coated with a thin film of silver and examined under a scanning electron microscope (JEOL/JSM-6000F, JEOL Ltd., Tokyo, Japan).

\section{Western blotting}

Cell lysates $(30 \mu \mathrm{g}$ protein) resolved on $10 \%$ SDS-PAGE were transferred to a polyvinylidene difluoride membrane (Millipore, Bedford, MA). For immunoblotting, we used antibodies against ezrin, VSV-G, phospho-ezrin (Tyr353), phospho-p44/42 MAPK(Erk1/2) (Thr202/ Tyr204), p44/42 MAPK (Erk1/2), phospho-AKT 
(Ser473), AKT and GAPDH. The immunoreactive proteins were visualized using the ECL western blotting system (Amersham International, little Chalfont, UK), and densitometric analysis was performed using the Image Pro-Plus Software.

\section{Indirect immunofluorescence}

Cells were plated on glass coverslips for 24 hours, fixed with $3.7 \%$ paraformaldehyde for 20 minutes and then permeabilized with PBS containing $0.05 \%$ Triton X-100 for 10 minutes. The cells were then blocked with $1 \%$ BSA in PBS for 1 hour, followed by adding of primary antibodies diluted in blocking buffer at $4^{\circ} \mathrm{C}$ overnight at the following concentrations: anti-ezrin (serum was diluted 1:150) and anti-VSV-G (serum was diluted 1:75). Subsequently, the cells were washed with PBS and then incubated for 1 hour in either the goat-anti-mouse IgG TRITC-conjugated antibodies or the goat-anti-rabbit IgG FITC-conjugated antibody, both of which were diluted in the blocking buffer (1:60). Afterwards, 4',6diamidino-2-phenylindole (DAPI) was used for nuclear counter-staining. Finally, the cells were mounted in the fluorescent mounting medium (Applygen Technologies Inc., Beijing, China) and viewed with under a fluorescence microscope (BH2-RFCA; Olympus Optical Co., Ltd, Tokyo, Japan).

\section{Cell growth assay and flow cytometry analysis}

In vitro cell growth was assessed using the Dojindo Cell Counting Kit-8 (Dojindo Laboratory, Kumamoto, Japan) according to the supplier's recommendations. Clones were plated in tissue culture plates at a density of $1 \times$ $10^{3}$ cells in $0.1 \mathrm{~mL}$ of culture medium per well and grown in DMEM with $10 \% \mathrm{FCS}$ in $5 \% \mathrm{CO}_{2}$ at $37^{\circ} \mathrm{C}$. The number of cells per well was quantified by daily measurement of the absorbance at $450 \mathrm{~nm}$ for 7 days after plating. All experiments were performed in triplicate on three separate occasions. Replicate growth curves were plotted for each of the clones and compared to control cells grown under identical culture conditions. To determine the cell cycle distribution, $5 \times 10^{5}$ cells were plated in $60-\mathrm{mm}$ dishes and cultured for periods of up to 2 days. The cells were then collected by trypsinization, fixed with $70 \%$ ethanol, washed with PBS, resuspended in $1 \mathrm{~mL}$ of $0.01 \mathrm{M}$ PBS with RNase and $50 \mu \mathrm{g} / \mathrm{mL}$ propidium iodide, incubated for 20 minutes in the dark at room temperature and analyzed by flow cytometry using a FACS Calibur (Becton Dickinson, Bedford, MA).

\section{Colony formation assay}

An equal amount of $1 \%$ Noble agar solution prewarmed to $40^{\circ} \mathrm{C}$ was added to DMEM containing $20 \%$ FCS pre-warmed to $37^{\circ} \mathrm{C}$ to make a $0.5 \%$ agar solution. After rapid mixing by inversion, the resultant solution was added to 24 -well plates $(0.5 \mathrm{~mL} /$ well). After reaching 70 to $80 \%$ confluence, the cells were trypsinized, washed with D-Hanks three times and diluted in Noble agar solution $(0.35 \%$ Noble agar in DMEM with $10 \%$ FCS) at $37^{\circ} \mathrm{C}$. The cell suspensions were then added into 24 -well plate with a $0.5 \%$ agar layer (200 cells in $0.5 \mathrm{~mL}$ ) (three wells per condition). The plates were incubated at $37^{\circ} \mathrm{C}$ with $5 \% \mathrm{CO}_{2}$ for three weeks. The colony formation ability under each condition was assessed using untreated cells as control.

\section{Transfilter migration and invasion assays}

Transfilter assays were performed with $8.0-\mu \mathrm{m}$ pore inserts in 24-well BioCoat Chambers (Becton Dickinson) using $5 \times 10^{4}$ cells in serum-free DMEM. The DMEM medium with $10 \%$ FCS was placed in the lower chambers as a chemoattractant. For invasion assays, Matrigelcoated transwell chambers were used. For migration and invasion assays, the cells were removed from the upper surface of the filter by scraping with a cotton swab after 12 and 24 hours in culture respectively. Migrated cells and invasive cells were fixed and stained with the crystal violet reagent. Mean values of the data obtained from three separate chambers were presented.

\section{Tumor transplantation and spontaneous/experimental metastasis}

Female BALB/c nude mice (body weight, 15 to $17 \mathrm{~g}$ ) were bred under specified pathogen-free conditions $\left(26^{\circ} \mathrm{C}, 70 \%\right.$ relative humidity and a 12 -h light/12-h dark cycle) in a germ-free environment with free access to food and water. To examine the effects of ezrin on tumor cell proliferation and metastasis in vivo, Mia ez22-B, Mia pcb6, Mia ezsi-scram and Mia ezsi-E $\left(5 \times 10^{6}\right.$ cells $/ 100 \mu \mathrm{L}$ normal sodium/ mouse) were used. For spontaneous metastasis, the cells were injected into the inferior of pancreas capsule of the nude mice, whereas for experimental metastasis, the cells were injected into the tail vein of the nude mice. The mice were monitored every 2 to 3 days and sacrificed 10 weeks after injection. Tumors were excised, and metastasis in the lung, viscera, liver, draining lymph nodes and other organs were assessed. These tumors were embedded into paraffin. Histological analysis of the tissue sections stained with hematoxylin and eosin were performed to confirm the presence of metastasis in the various organs. Based on the gross and histological analyses, animals were assessed as positive or negative with respect to metastasis. Animal handling and experimental procedures were approved by the Peking Union Medical College Hospital animal experiments committee. It was also in accordance with the recommendations by the regional and country animal ethics committee. 
Patients, specimens and immunohistochemistry

This study was approved by the Institutional Review Board of Peking Union Medical College Hospital, Chinese Academy of Medical Sciences (CAMS) and Peking Union Medical College (PUMC). Surgically resected specimens from 70 patients (age range, 29 to 78 years) with PDAC were examined. This patient population represented a randomly selected subgroup from a clinical series including all patients who underwent surgical resection between June 1998 and December 2005 in the Department of Surgery at Peking Union Medical College Hospital. The diagnosis of PDAC, histological grading and pathologic staging were re-evaluated and/or confirmed by two independent pathologists. PanIN lesions $(\mathrm{n}=34)$ and CP $(\mathrm{n}=28)$ were assessed and graded in the pancreatic tissues adjacent to the tumor in hematoxylin and eosin-stained slides.

Immunostaining for ezrin was performed using the primary rabbit polyclonal antibody against human ezrin (diluted $1: 150$ ) at $4^{\circ} \mathrm{C}$ overnight after antigen retrieval in $10 \mathrm{mM}$ sodium citrate buffer ( $\mathrm{pH}$ 6.0) for 15 minutes at $95^{\circ} \mathrm{C}$, followed by incubation with an HRP-labeled antirabbit antibody for 1 hour. Immunostaining and clinicopathologic features were evaluated microscopically by two pathologists. Ezrin-specific immunoreactivity was scored by estimating the percentage of labeled tumor cells as follows: score $0,<25 \%$ positive cancer cells; score,$+ 25-50 \%$ positive cancer cells; score,$++ 50-75 \%$ positive cancer cells; and score,$+++>75 \%$ positive cancer cells. Specimens were considered positive for ezrin expression when the scores were + to +++ and were considered negative for ezrin expression when the score was 0 . Pictures were collected using the MicroView MVC2000 image apparatus and software.

\section{Statistical analysis}

Each experiment was performed three to four times. All of the data were expressed as mean \pm SD. Statistical analysis was performed using the Microsoft Excel software package. Comparisons between groups were conducted using Welch's $t$ test. Correlation of ezrin immunoreactivity with clinicopathologic parameters were analyzed by Fisher's exact test. Differences were considered statistically significant at $P<0.05$.

\section{Results}

Establishment of ezrin overexpression monoclones and silencing of the ezrin gene in MiaPaCa-2 cells

To study the function of the Vil2 gene in $\mathrm{MiaPaCa}-2$ cells, the pcb6-ezrin-VSV-G vector was adopted to stably overexpress the ezrin protein, and the pcb6 vector was used as a control. For ezrin silencing, the three ezrin siRNAs, described in the Materials and methods, were synthesized and transfected into MiaPaCa-2 cells.
Western blot analysis showed the No. 2 siRNA inhibited ezrin more efficiently (data not shown). Thus, the No. 2 and No. 3 siRNA sequences were cloned into the pSilencer 2.1 U6 vector. G418-screened MiaPaCa-2 cells were used for analysis, and the stable cell clones Mia ez22-B, Mia pcb6, Mia ezsi-B, Mia ezsi-E and Mia ezsi-scram were selected. Western blot analysis showed that ezrin protein expression was efficiently increased by 3.8 folds in the Mia ez22-B cells compared to the Mia pcb6 cells (Figure 1A, B). It was also shown that ezrin protein expression was efficiently decreased by $70.5 \%$ and $90.1 \%$ in the Mia ezsi-B and Mia ezsi-E cells, respectively, compared to that in the Mia ezsi-scram cells (Figure 1C). In addition, immunoflurescence staining using the VSV-Gtagged ezrin antibody further confirmed its stable overexpression in the MiaPaCa-2 cells (Figure 1D, E), which also showed that ezrin protein expression was dramatically decreased in the Mia ezsi-E cells (Figure 1G) compared to that in the Mia ezsi-scam cells (Figure 1F).

\section{Ezrin overexpression enhancing the formation of cell protrusions and cell microvilli}

To explore whether ezrin is involved in cytoskeleton modulation, we studied the morphological changes of the stable transfectants by scanning electron microscopy (SEM). Compared to those in the Mia pcb6 cells, there was a sharp increase in the numbers of membrane protrusions and more elongated membrane projections in the Mia ez22-B cells (Figure 2B). The Mia pcb6 cells exhibited a smooth edge and fewer projections (Figure 2A). In contrast, compared to those in the Mia ezsiscram cells, a dramatic decrease in the numbers of membrane protrusions and smooth edges were observed in the Mia ezsi-E cells (Figure 2D), and the Mia ezsi-scram cells showed more projections and more elongated membrane projections (Figure 2C). The morphologic changes suggest possible alteration of tumor cell behavior.

\section{Ezrin altering anchorage-independent growth ability without affecting cell proliferation or cell cycle distribution in vitro}

A series of experiments were conducted to determine the effect of different ezrin protein levels on the proliferation of MiaPaCa- 2 cells in vitro. The effect of the ezrin protein on cell growth rate was examined by the CCK- 8 assay. The change in the ezrin protein level had no significant effect on the cell growth rate in vitro (Figure 3A). The flow cytometry assay further showed that changes in the ezrin protein level did not affect the cell cycle distribution (Figure 3B). To further characterize the effect of ezrin on anchorage-independent growth ability, the colony forming assay was performed. Ezrin overexpression facilitated the anchorage-independent growth ability of the Mia ez22-B cells when compared to that of the Mia pcb6 cells, and 

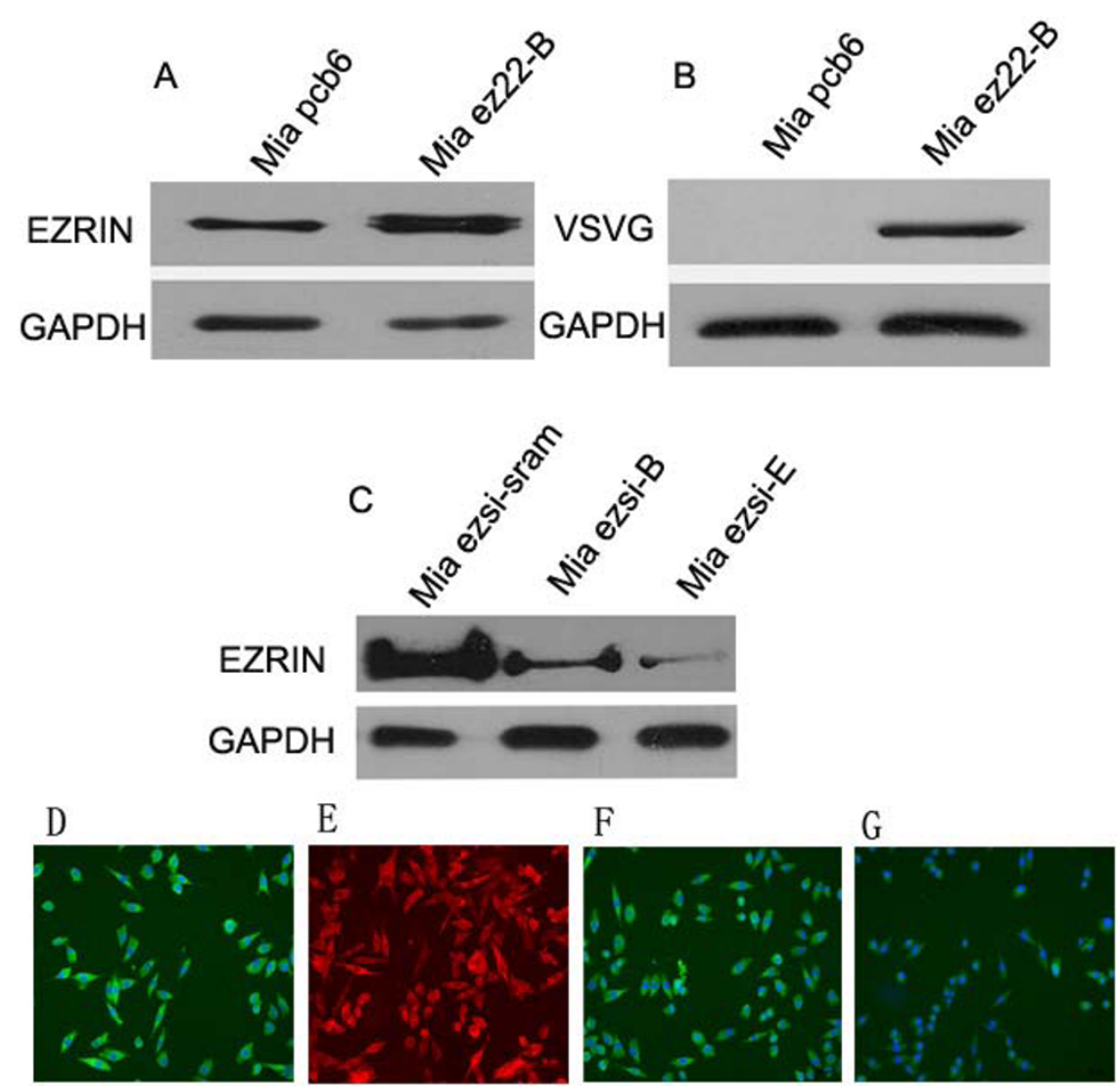

Figure 1 Stable overexpression and silencing of ezrin in MiaPaCa-2 cells. (A) Western blot showed the ezrin protein was overexpressed in the Mia ez22-B cells compared to the Mia pcb6 cells using an ezrin antibody. The relative ezrin protein level was quantified by densitometry analysis. The ezrin protein was efficiently increased by 3.8 folds in the Mia ez22-B cells. (B) Ectopic expression of ezrin in the Mia ez22-B cells was detected using a VSV-G antibody (VSV-G tag in the pcb6-ezrin vector). (C) The expression level of ezrin protein was dramatically decreased by $70.5 \%$ and $90.1 \%$ in the Mia ezsi-B and the Mia ezsi-E cells, respectively, compared to that in the Mia ezsi-scram cells. GAPDH was used as a loading control. (D) The Mia pcb6 cells were stained with the ezrin antibody and a FITC-conjugated second antibody to detect the ezrin protein expression. (E) The vector tag VSV-G antibody and a Rhodamine-conjugated second antibody were used to detect the exogenous ezrin protein expression. (F, G) The Mia ezsi-scram and the Mia ezsi-E cells were stained with the ezrin antibody and the FITC-conjugated second antibody to detect the ezrin protein expression.

ezrin silencing decreased the anchorage-independent growth ability in the Mia ezsi-E cells compared to that of the Mia ezsi-scram cells (Figure 3C). Statistical analysis showed that the anchorage-independent growth ability of the tumor cells in soft agar was increased by $103.1 \%$ in the Mia ez22-B cells compared to that in the Mia pcb6 cells, and it was decreased by $54.3 \%$ in the Mia ezsi-E cells compared to that in the Mia ezsi-scram cells (Figure 3D). These results indicated that ezrin could enhance the anchorage-independent growth ability of MiaPaCa-2 cells.

\section{Ezrin increasing the cell motility and invasion ability of MiaPaCa-2 cells}

Cell motility ability was examined by determining of the migration rate through a polyethylene filter in the absence of Matrigel. The migration rate of the Mia ez22-B cells (Figure 4b) was greatly increased compared to that of the Mia pcb6 cells (Figure 4a). The average cell number of the Mia ez22-B cells migrating to the lower chamber was $105 \pm 5.06$ per high-power field $\left(0.312 \mathrm{~mm}^{2} / \mathrm{HPF}\right)$, compared to $40.4 \pm 2.86 / \mathrm{HPF}$ of the Mia pcb6 cells. The quantitative analysis showed that cell migration to the lower chamber was increased by 1.59 folds in the Mia ez22-B cells compared to that in the Mia pcb6 cells $(P<0.01)$ (Figure $4 \mathrm{c})$. Compared to that of the Mia ezsi-scram cells (Figure $4 \mathrm{~d}$ ), the migration rate of the Mia ezsi-E cells (Figure 4e) was greatly decreased. The average cell number of the Mia ezsi-E migrating to the lower chamber was $5.39 \pm 0.32 / \mathrm{HPF}$, compared to $36.7 \pm 1.453 / \mathrm{HPF}$ of the Mia ezsi-scram cells. The quantitative analysis showed that cell migration to the lower chamber were decreased by $58.3 \%$ in the Mia ezsi-E cells compared to that in the Mia ezsiscram cells $(P=0.00003)$ (Figure $4 \mathrm{f})$. 

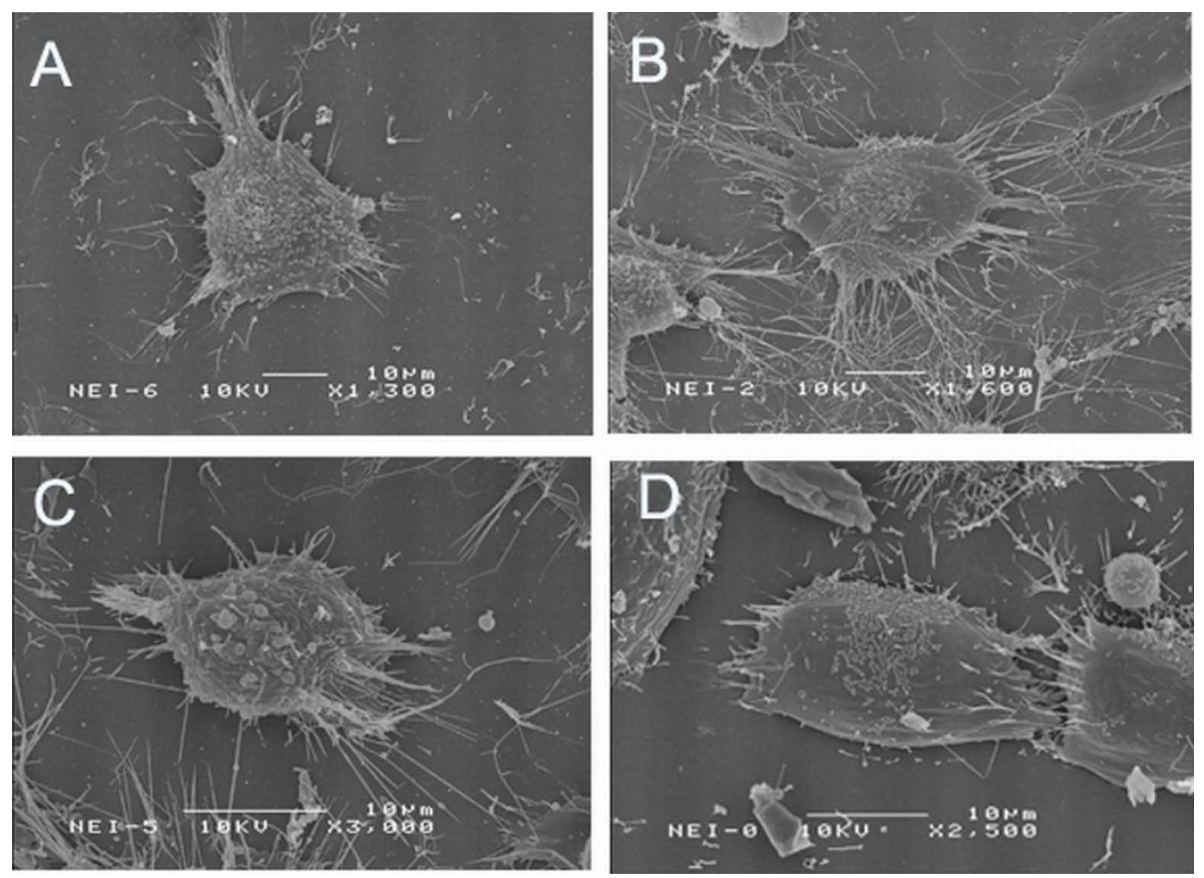

Figure 2 Scanning electron microscopy showed increased formation of membrane protrusions and microvilli in the Mia ez22-B cells (B) compared to that in the Mia pcb6 cells (A). A sharp decrease of the membrane protrusions and smooth edge in the Mia ezsi-E cells (D) compared to those in the Mia ezsi-scram cells (C).

We next examined whether ezrin can affect the invasion activity of pancreatic cancer cells by the Matrigel invasion assay. Cell invasive activity was also dramatically enhanced in the Mia ez22-B cells (Figure 5b) compared to that in the Mia Pcb6 cells (Figure 5a). The average cell number invading to the lower chamber for 24 hours was $314 \pm 46.93$ /HPF in the Mia ez22-B cells, compared to $144 \pm 20.42 / \mathrm{HPF}$ in the Mia pcb6 cells. The quantitative analysis demonstrated that the number of the Mia ez22-B cells invading to the lower chamber was increased by 1.18 folds compared to that of the Mia pcb6 cells $(P=0.0045)$ (Figure $5 \mathrm{c})$. In addition, cell invasive activity was also dramatically decreased in the Mia ezsi-E cells (Figure 5e) compared to that in the Mia ezsi-scram cells (Figure 5d), which was $20.6 \pm 4.06 / \mathrm{HPF}$ and $158 \pm 17.85 / \mathrm{HPF}$, respectively. The quantitative analysis showed that the number of Mia ezsi-E cells invading to the lower chamber was decreased by $87.0 \%$ compared to that of the Mia ezsi-scram cells $(P=$ 0.0017) (Figure 5f). Both the increase and decrease of cell motility and invasion might result from morphological alterations of the MiaPaCa-2 cells, such as increased protrusions and microvilli.

\section{Ezrin overexpression inducing Erk $1 / 2$ activation}

The results described above indicate that ezrin is involved in the motility and invasion of MiaPaCa-2 cells. Erk1/2 signaling has been shown to disrupt actin stress fibers, which in turn increases cell motility by changing actin dynamics and decreasing of cell adhesion [29]. The PI3-kinase pathway has also been shown to be responsible for RAC-dependent membrane ruffling downstream of the Ras signaling pathway [30]. It has been recently reported that phosphorylation of ezrin is required for metastatic behavior of tumor cells [31]. Our results showed that ezrin overexpression increased the level of phosphorylated-Erk1/2 protein without altering the level of total Erk1/2 in MiaPaCa-2 cells. However, there was no obvious alteration in the level of phosphorylatedErk1/2 protein in the Mia ezsi-E cells. Those results suggest that the Erk1/2 pathway might participate in the ezrin-mediated cell growth, motility and invasion. Moreover, there were no obvious changes in the protein levels of Akt, phosphorylated-Akt and phosphorylatedezrin (Tyr353) in both the ezrin silencing and the ezrin overexpression clones of MiaPaCa-2 cells (Figure 6).

\section{Ezrin overexpression promoting metastasis of MiaPaCa-2 cells in vivo}

Tumorigenicity and metastasis of the Mia ez22-B, Mia pcb6, Mia ezsi-E and Mia ezsi-scram cells were compared in xenograft models. Spontaneous and experimental metastasis in mouse models were examined to study the role of ezrin in the growth and metastasis of Mia$\mathrm{PaCa}-2$ cells in vivo. In the spontaneous metastasis models, the tumor incidences were $100 \%(8 / 8)$ in the 


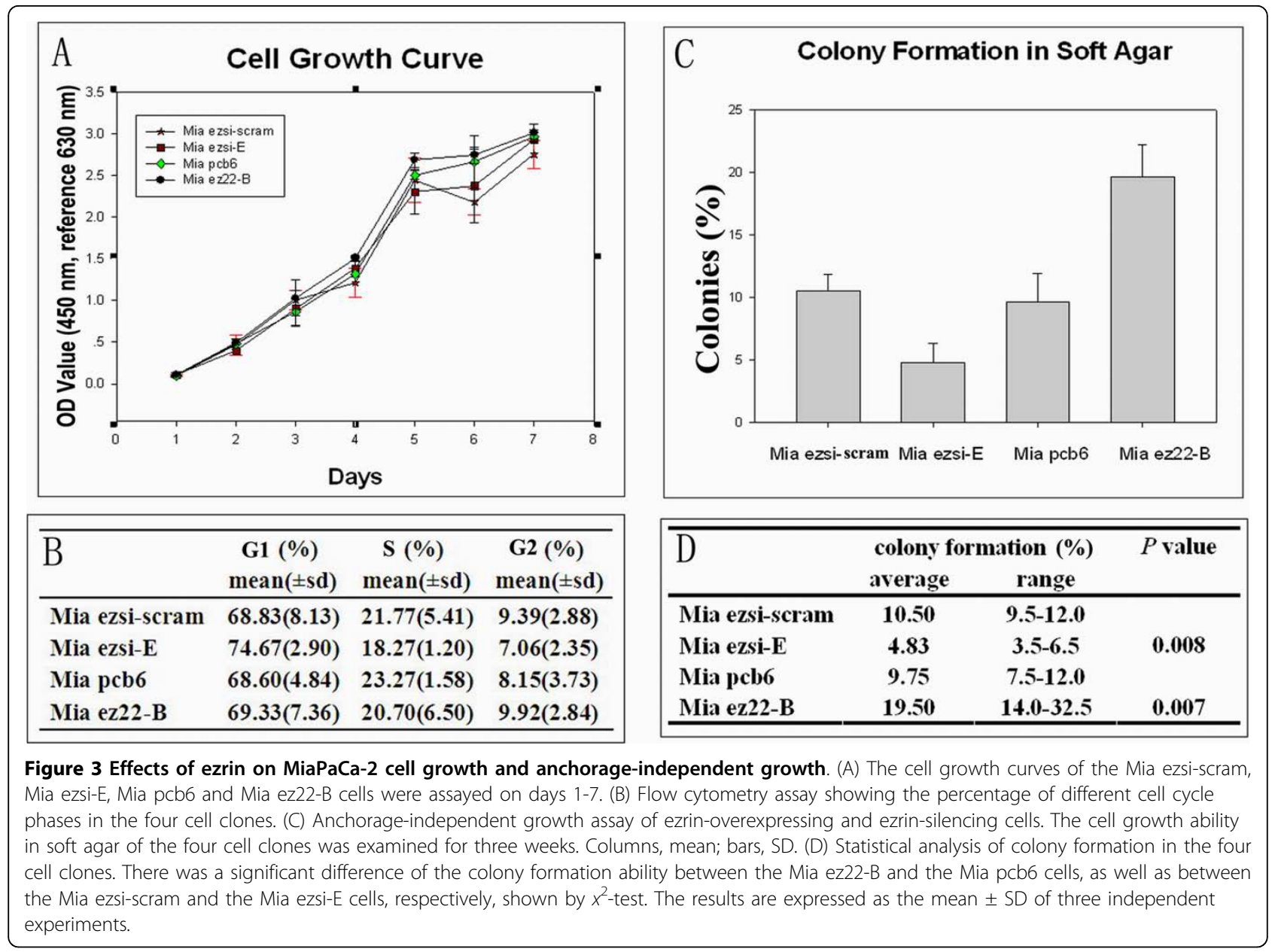

Mia ez22-B, Mia pcb6, Mia ezsi-E and Mia ezsi-scram cell-treated animals. The body and tumor weight of the experimental animals showed no apparent differences among the four cell clone-treated animals $(P>0.05)$ (Table 1). Six out of the eight nude mice treated with the Mia ez22-B cells developed mesentery lymph node metastasis, whereas only one out of the eight Mia pcb6treated mice developed mesentery lymph node metastasis $(P<0.05)$. In addition, one out of the eight Mia ez22-B-treated mice displayed a diaphragm metastasis. Moreover, one out of the eight Mia ezsi-scram-treated mice developed mesentery lymph node metastasis, whereas no metastasis was found in the Mia ezsi-E-treated animals $(P>0.05)$; none of the four groups was found to be present with internal organ metastasis (Table 1). In the experimental metastasis mouse models, two out of the eight Mia ez22-B-treated mice exhibited tumor metastasis, with one metastasis found in the spinal cord and the other in the pelvic cavity and adrenal gland area. No metastasis was found in the nude mice treated with the other three cell lines $(P>0.05)$. These data indicate that ezrin overexpression can induce metastasis in vivo in spontaneous metastasis mice models; however, ezrin silencing had no obvious effect on the metastatic potential of $\mathrm{MiaPaCa}-2$ cells.

\section{Immunohistochemical analysis of ezrin expression in pancreatic ductal carcinoma samples}

To study the role of ezrin in pancreatic cancer, we analyzed its expression pattern in 70 PDAC patients and 61 normal pancreatic or paraneoplastic tissues (more than $1.5 \mathrm{~cm}$ away from the tumor). Ezrin was not detectable in normal pancreatic ducts and acini (Figure 7A); however, 64 PDAC samples were found to be ezrin positive $(91.4 \%, 64 / 70)$ (Figure 7B-D, Table 2), suggesting that ezrin was overexpressed in human PDAC and that ezrin expression was likely associated with pancreatic cancer development. To determine whether or not ezrin expression was correlated with any clinical-pathological parameters, the relationship between ezrin expression and histological grading, as well as clinical staging was analyzed. We found that ezrin expression was not correlated with histological grading, pathologic stage, lymph node status or the depth of invasion (Table 2). 

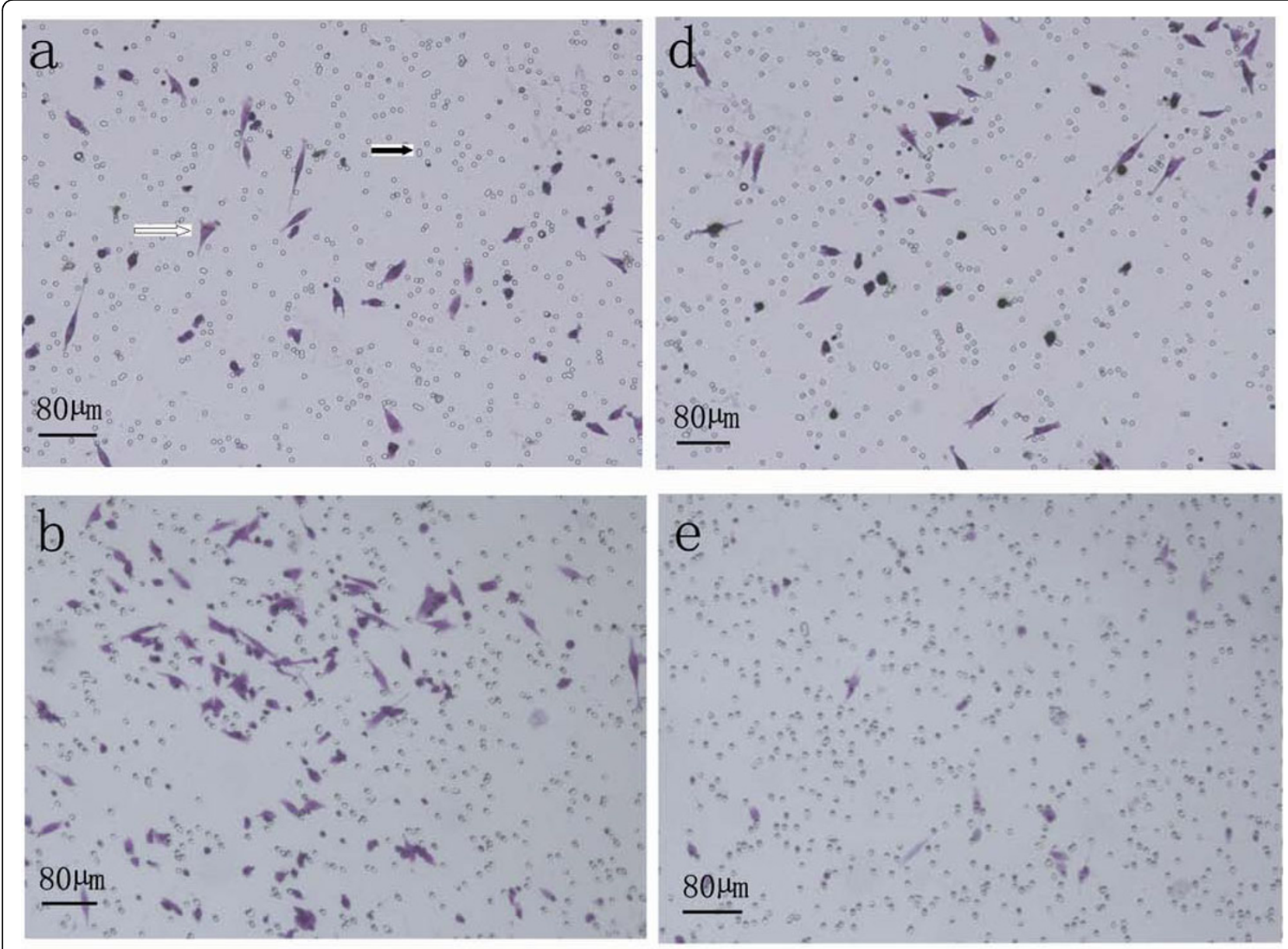

\section{Cell Migration Assay}
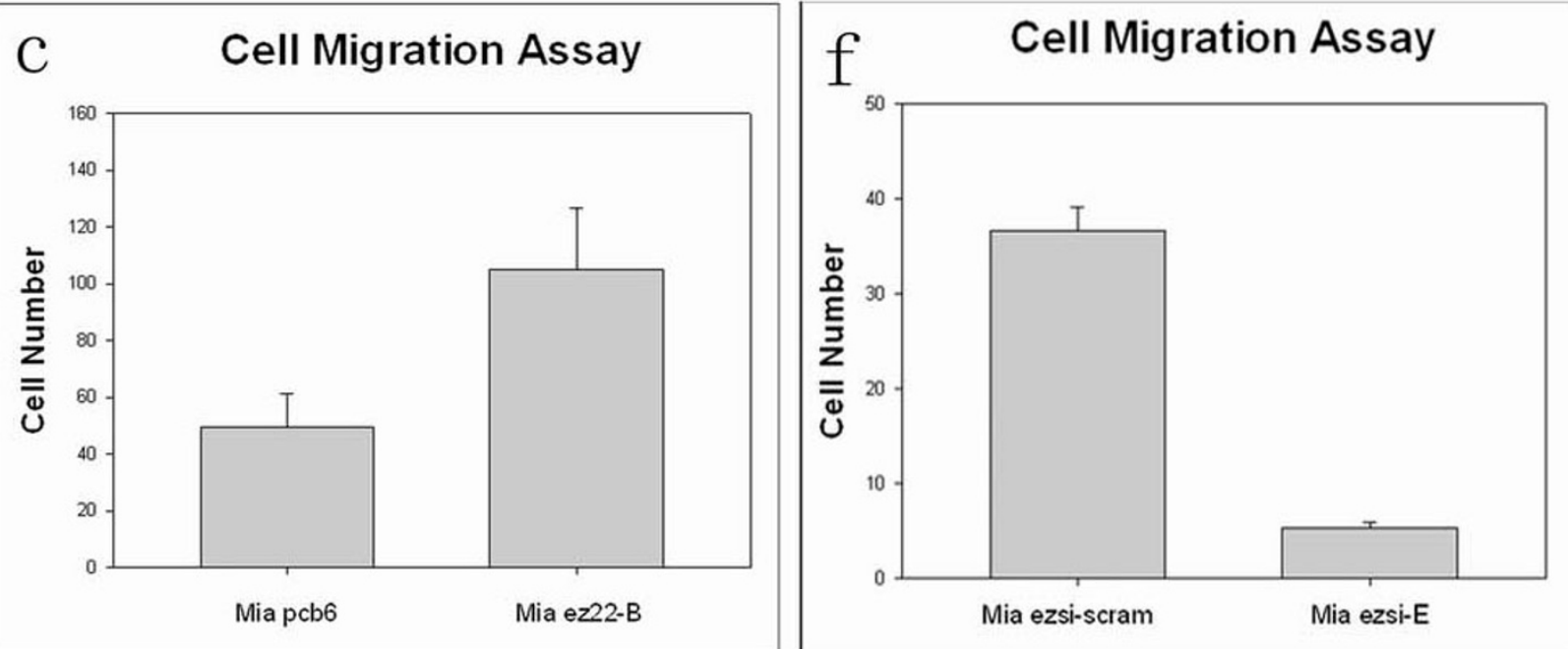

Figure 4 Effects of ezrin on cell motility in vitro. BioCoat Chambers were used to detect cell migration and representative fields were photographed. Black-arrows indicate the $8-\mu \mathrm{m}$ membrane pores, and hollow-arrows indicate cells that had migrated through the membrane, which were stained with Crystal Violet (a). Cell migration of the Mia ez22 (b), Mia pcb6 (a), Mia ezsi-E (e) and Mia ezsi-cram (d) cells after 12 hours were shown. The cells migrating to the lower chambers were analyzed. For quantification, the cells were counted in 10 random fields under a light microscope ( $\times 400)$. Compared to the Mia pcb6 cells, the Mia ez22-B cells showed a significant increase in migration by $x^{2}$-test (c). The decrease in the numbers of migrated cells in the Mia ezsi-E cells compared to those of the Mia ezsi-scram cells was statistically significant, shown by the $\mathrm{x}^{2}$-test (f). Columns: mean; bars: SD. 


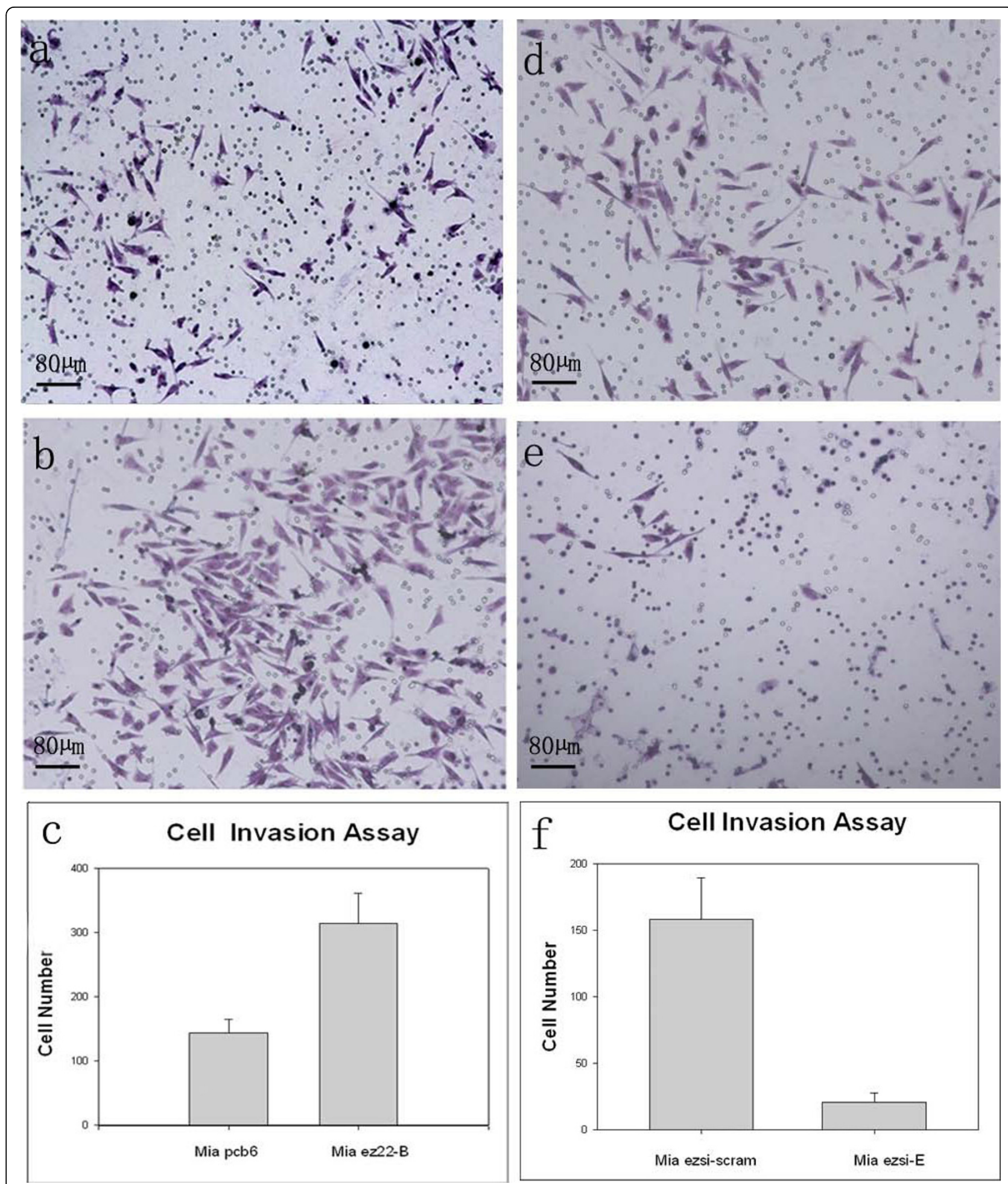

Figure 5 Effects of ezrin on cell invasion in vitro. Matrigel-coated transwell chambers were used to detect cell invasion and representative fields were photographed. Cell invasion of the Mia ez22 (b), Mia pcb6 (a), Mia ezsi-E (e) and Mia ezsi-cram (d) cells after 24 hours were shown. The cells invading to the lower chambers were analyzed. Compared to the Mia pcb6 cells, the Mia ez22-B cells showed a significant increase in invasion by $x^{2}$-test (c). The decrease in the numbers of invasive cells in the Mia ezsi-E cells compared to those of the Mia ezsi-scram cells was statistically significant, shown by the $x^{2}$-test (f). Columns: mean; bars: SD. 


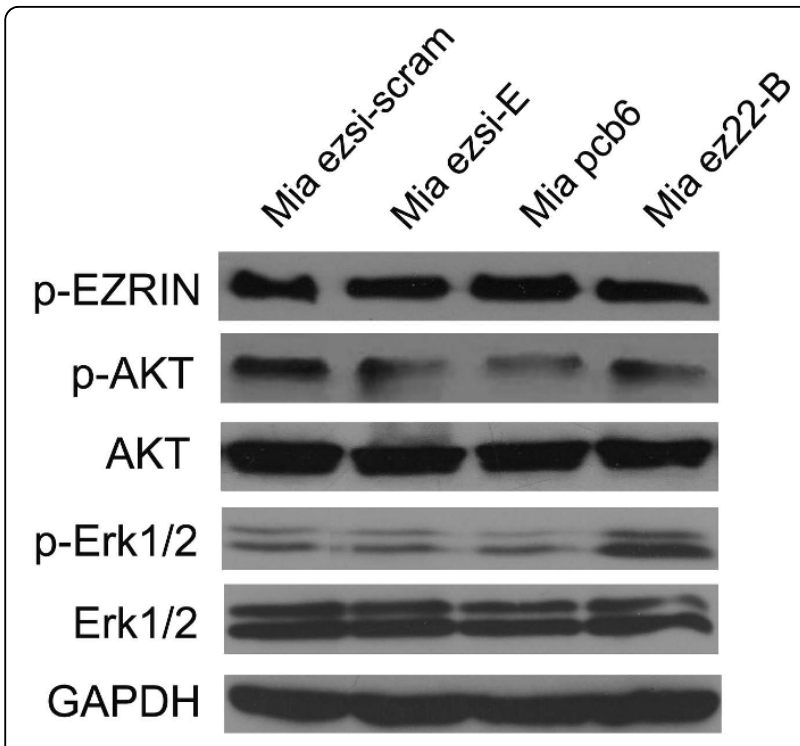

Figure 6 Ezrin overexpression increasing the level of phosphorylated Erk1/2 in MiaPaCa-2 cells. The levels of phosphorylated-ezrin, total AKT, phosphorylated-AKT, total Erk1/2 and phosphorylated Erk1/2 were determined by western blot in the Mia ezsi-scram, Mia ezsi-E, Mia pcb6 and Mia ez22-B cells. GAPDH was used as a loading control.

Ezrin expression in the tubular complexes in CP and PanIN, as well as in the proliferated intercalated ducts in the pancreatic tissue adjacent to PDAC

We then investigated the role of ezrin in precancerous lesions, including the tubular complexes in CP and PanIN that are considered to be precancerous lesions of PDAC. In total, 24 out of 28 (85.7\%) samples displayed positive staining of ezrin in the tubular complexes (ductal-like cells, Figure 8E). 33 out of 34 PanIN cases (97.1\%) were ezrin positive (Figure $8 \mathrm{~B}-\mathrm{D}$ ). As previously reported, PanIN can be classified into three main stages (1, 2 and 3) based on hyperplasia status and morphology of the epithelial cells. In this study, 9 PanIN-1, 13 PanIN-2 and 12 PanIN-3 samples were examined. Ezrin expression was observed in $8 / 9$ (88.9\%) of the PanIN-1 cases, $13 / 13(100 \%)$ of PanIN-2 and $12 / 12$ (100\%) of PanIN-3 (Figure 8B-D). No significant differences in ezrin-positive staining were found among the three classes of PanIN lesions $(P>0.05)$. We also observed that ezrin was expressed in the intercalated duct cells (Figure 8A) in pancreatic tissue adjacent to the adenocarcinoma. These results indicate that ezrin expression is associated with early stages of pancreatic cancer development.

\section{Discussion}

Ezrin is the best characterized member in the ERM family; it shares the common membrane-binding $\mathrm{N}$ terminal FERM domain with band-4.1 family members [32]. Ezrin linking the cell membrane to actin cytoskeleton allows a cell to interact with its microenvironment and provides an "intracellular scaffolding" that facilitates signal transduction through a number of growth factor receptors and adhesion molecules [2,11,33]. Positioned at the cell membrane-cytoskeleton interface, ezrin may be a nexus in the metastatic phenotype, playing a central, necessary and early role in the process of metastasis [22]. Upon threonine and tyrosine phosphorylation, ezrin assumes an active, "open" conformation and, in turn, moves to the cell membrane and directly or indirectly tethers F-actin to the cell membrane. Ezrin resides at the nexus of multiple pathways regulating cellular behavior that can influence metastatic potential, including cell survival, motility, invasion and adherence. Ezrin participates in several crucial signal transduction pathways, including the MAPK, AKT, Rho kinase and CD44 pathways, promoting cytoskeletal reorganization and subsequent morphogenetic alterations $[3,5,8,11]$. Highlevel ezrin expression was observed in many tumor cell lines, such as breast carcinoma and rhabdomyosarcoma cell lines [19-21]. Ezrin overexpression was also been observed in borderline lesions and pancreatic cancer tissues and associated with tumor malignant transformation and metastatic potential [23-26]; however, its role and mechanisms remain elusive.

The invasion of cells into the surrounding tissue is a multi-step action that requires cell-cell contact, cell motility and degradation of the extracellular matrix by matrix metalloproteinases [34,35]. Here we demonstrated that ezrin was involved in the cytoskeleton modulation by SEM, showing the ezrin-induced changes in cell protrusions, cell microvilli and pseudopodia

Table 1 Ezrin induces enhanced tumor metastasis in vivo

\begin{tabular}{|c|c|c|c|c|c|c|c|c|}
\hline \multirow[t]{2}{*}{ groups } & \multicolumn{2}{|c|}{ body weight (g) } & \multicolumn{2}{|c|}{ tumor weight(g) } & \multirow[t]{2}{*}{ tumor incidence } & \multicolumn{3}{|c|}{ metastasis } \\
\hline & average & range & average & range & & MLN & Dia & 10 \\
\hline Mia pcb6 & 18.14 & $13.9-20.7$ & 3.08 & $1.55-4.95$ & $8 / 8$ & $1 / 8$ & $0 / 8$ & $0 / 8$ \\
\hline Mia ez22-B & 20.94 & $15.7-24.2$ & 3.84 & $1.17-5.80$ & $8 / 8$ & $6 / 8^{*}$ & $1 / 8$ & $0 / 8$ \\
\hline Mia ezsi-scram & 18.35 & $13.5-21.3$ & 3.22 & $2.50-5.25$ & $8 / 8$ & $1 / 8$ & $0 / 8$ & $0 / 8$ \\
\hline Mia ezsi-E & 18.84 & $14.0-25.0$ & 3.02 & $2.30-4.23$ & $8 / 8$ & $0 / 8$ & $0 / 8$ & $0 / 8$ \\
\hline
\end{tabular}

MLN: mesentery lymphoid nodes Dia: diaphragm IO: internal organs

* Statistically different $(P<0.05)$ 

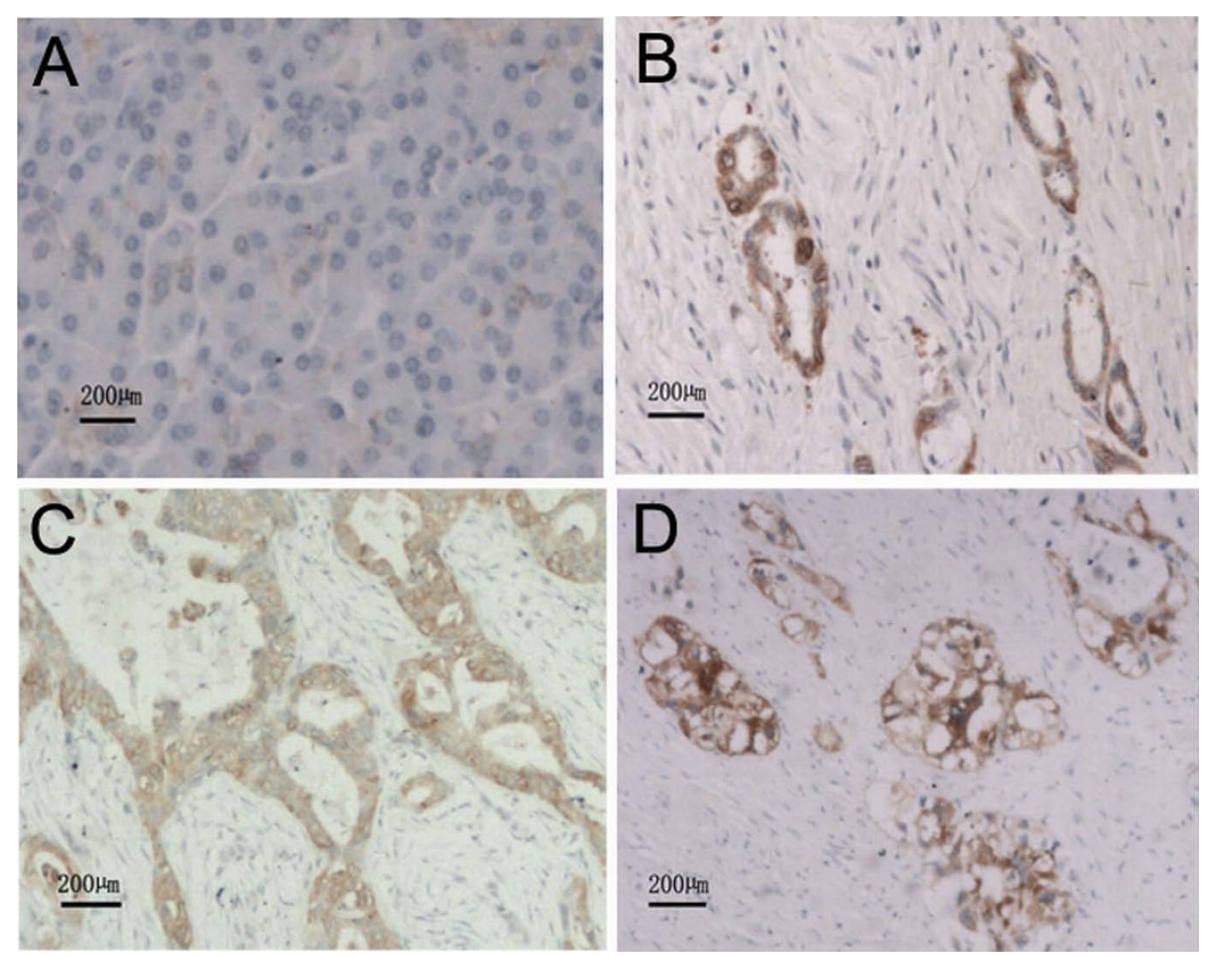

Figure 7 Ezrin expression in normal pancreatic tissue and pancreatic ductal adenocarcinoma shown by immunohistochemistry. (A) Normal pancreatic tissue. (B) Well-differentiated pancreatic ductal adenocarcinoma. (C) Moderate-differentiated pancreatic ductal adenocarcinoma. (D) Poor-differentiated pancreatic ductal adenocarcinoma.

compared to the control cells. Consistent with these results, the chamber migration and invasion assays confirmed that ezrin expression could alter the cell migration and invasion abilities of pancreatic cancer cells. Ezrin is a cytoskeletal protein that might affect the assembly of cytoskeletal elements at the cytoplasmic face of the membrane and the nuclear skeleton, which would then facilitate cell migration and invasion. These results were in agreement with the previous reports demonstrating that changes in cytoskeleton might be a key factor in regulating neoplastic progression and tumor growth $[13,22,32,36]$.

Our results showed that increased level of the ezrin protein was correlated with an increase in anchorageindependent growth of tumor cells, consistent with the previous finding in glioma cells [13]. We also established experimental and spontaneous mice models and showed that ezrin overexpression could enhance tumor metastasis in vivo, consistent with our observations in the cell motility/invasion and soft agar colony formation assays in vitro.

Our results also showed that ezrin overexpression could induce metastasis in vivo in the spontaneous metastasis mouse model; however, ezrin silencing exerted no obvious effect on the metastatic potential of MiaPaCa-2 cells. These observations might be explained by the fact that MiaPaCa-2 cells is a cell line with low metastatic potential; therefore, the effect of ezrin silencing on metastasis may not be obvious. In addition, ezrin silencing might affect other signal pathway.

A striking feature of ezrin overexpression was the increased formation of surface protrusions that play essential roles in cell motility [37]. Aside from the increased formation of protrusions, we proposed another possible mechanism for the effects of ezrin on cell invasion. Our results showed that phosphorylated Erk1/2 was markedly increased in the Mia ez22-B cells, although no significant changes were observed in the Mia ezsi-E cells compared to the controls. Activation of Erk $1 / 2$ by ezrin in MiaPaCa- 2 cells indicates that the Erk1/2 MAPK pathway is one of the mediators of ezrin signaling. Therefore, the Erk1/2 pathway may also be involved in ezrininduced cell motility, invasion and morphological changes in pancreatic ductal adenocarcinoma. This result is consistent with previous studies showing that the Erk1/2 pathway is involved in the reappearance of the actin cytoskeleton, allowing for the extension of ruffles into the active protrusions that are required for cell motility and, therefore contributing to the alteration of cell motility and invasion [29,30]. Although the phosphatidylinositol 3-kinase/Akt pathway is involved in ezrinmediated cell survival [11], we did not find corresponding 
Table 2 Association between ezrin expression and clinico-pathologic variables in $\mathbf{7 0}$ patients with pancreatic ductal adenocarcinoma

\begin{tabular}{|c|c|c|c|c|}
\hline \multirow[t]{2}{*}{ variable } & \multirow[t]{2}{*}{ No. of patients } & \multicolumn{2}{|c|}{ ezrin expression } & \multirow[t]{2}{*}{$P^{*}$} \\
\hline & & $\begin{array}{l}\text { positive } \\
(n=64)\end{array}$ & $\begin{array}{l}\text { negative } \\
(n=6)\end{array}$ & \\
\hline \multicolumn{2}{|l|}{ Age } & & & 0.175 \\
\hline$<65$ & 53 & 47 & 6 & \\
\hline$>65$ & 17 & 17 & 0 & \\
\hline \multicolumn{2}{|l|}{ Gender } & & & 0.34 \\
\hline Male & 45 & 41 & 4 & \\
\hline Female & 25 & 23 & 2 & \\
\hline \multicolumn{2}{|c|}{ Histopathogic grading } & & & 0.4688 \\
\hline G1 & 8 & 8 & 0 & \\
\hline G2 & 38 & 34 & 4 & \\
\hline G3 & 24 & 22 & 2 & \\
\hline \multicolumn{2}{|c|}{ Depth of invasion } & & & 0.653 \\
\hline $\mathrm{T} 1$ & 2 & 2 & 0 & \\
\hline $\mathrm{T} 2$ & 17 & 15 & 8 & \\
\hline T3 & 46 & 42 & 4 & \\
\hline $\mathrm{T} 4$ & 5 & 5 & 0 & \\
\hline \multicolumn{2}{|c|}{ Pathologic stage } & & & 0.249 \\
\hline 1 & 5 & 5 & 0 & \\
\hline$\|$ & 16 & 14 & 2 & \\
\hline II & 41 & 39 & 23 & \\
\hline IV & 8 & 6 & 2 & \\
\hline \multicolumn{2}{|c|}{ LN metastasis } & & & 0.3304 \\
\hline Negative & 27 & 25 & 2 & \\
\hline Positive & 43 & 39 & 4 & \\
\hline
\end{tabular}

LN:Lymph node

*Fisher's exact test was used for analysis

evidence in either the ezrin-overexpressing or the ezrinsilencing MiaPaCa-2 cells. Although a recent study has shown that overexpression of pEzrin(Tyr353) in pancreatic cancers is associated with positive lymph node metastasis, less differentiation, pAkt overexpression, and shorter survival times [27], we did not observe any change of ezrin phosphorylation in either the ezrin overexpressing or the ezrin silencing $\mathrm{MiaPaCa}-2$ cells. Therefore, phosphorylation of ezrin may not affect the motility and invasion ability of MiaPaCa- 2 cells in vitro. Ezrin overexpression may be sufficient to confer metastatic potential [38], and ezrin silencing may reverse metastatic behavior, through other ways [21]. These underlying mechanisms require further elucidation.

Immunohistochemical analysis demonstrated that ezrin expression was elevated in PDAC samples compared to normal pancreatic tissues, which provided additional evidence supporting a functional role of ezrin in pancreatic cancer development. We also observed that ezrin was highly expressed in precancerous lesions, such as PanINs $(97.1 \%, 33 / 34)$ and tubular complexes in CP $(85.7 \%, 24 /$
28). These observations have further significance. The detection and treatment of early-stage, non-invasive PanINs has a major impact on pancreatic cancer survival. PanINs are morphologically classified into three grades, according to nuclear polarity, nuclear size (pleomorphism) and hyper-chromatic staining [39,40]. Despite complex associations between tumor cells and PanINs, histological and molecular evidence suggests that PanINs can gradually progress to PDAC, bearing genetic traits such as Ras mutations, Cyclin D1 overexpression and loss of p16 expression [41,42]. Because CP is also an independent risk factor for PDAC development [41], high ezrin expression proportion in CP and PanINs suggests that ezrin might be involved in the earliest stages of PDAC pathogenesis and could potentially serve as an indicator for those lesions progressing to the more advanced stage-PDAC. Ezrin was also expressed in the intercalated ducts in the pancreatic tissue that was adjacent to the adenocarcinoma, which was considered to be the origin in the pancreatic ducts and acini, as well as the starting point of PDAC development $[43,44]$. The results indicate that ezrin may play an important role in the early development of pancreatic ductal carcinoma.

In conclusion, we successfully overexpressed and silenced the ezrin protein expression in $\mathrm{MiaPaCa}-2$ cells, and found that changes in the ezrin protein level were correlated with changes in the formation of dynamic cell protrusions, motility, invasion and the ability of anchorage-independent growth, which are all tumor cells features. Based on these results, we propose that ezrin, by participating in the formation of cell protrusions and the enhancement of anchorage-independent growth ability, might promote invasion and metastasis in carcinogenesis. These processes may be attributed to the activation of the Erk $1 / 2$ pathway $[29,30]$. The high ezrin expression proportion in CP, PanINs and ezrin expression in intercalated duct cells suggest that ezrin might be involved in the earliest stages of PDAC pathogenesis and could potentially serve as an indicator for those lesions progressing to the more advanced stage, PDAC. These results indicate that blocking ezrin function may represent a novel and effective strategy for preventing pancreatic cancer progression, invasion and metastasis. In pancreatic precancerous lesions, such as PanINs and chronic pancreatitis, blocking ezrin function may have therapeutic effects that prevent these two diseases from progressing to pancreatic cancer.

\section{Conclusions}

We propose that ezrin might play functional roles in modulating morphology, growth, motility and invasion of pancreatic cancer cells, and that the Erk $1 / 2$ pathway may be involved in these roles. Moreover, ezrin may 

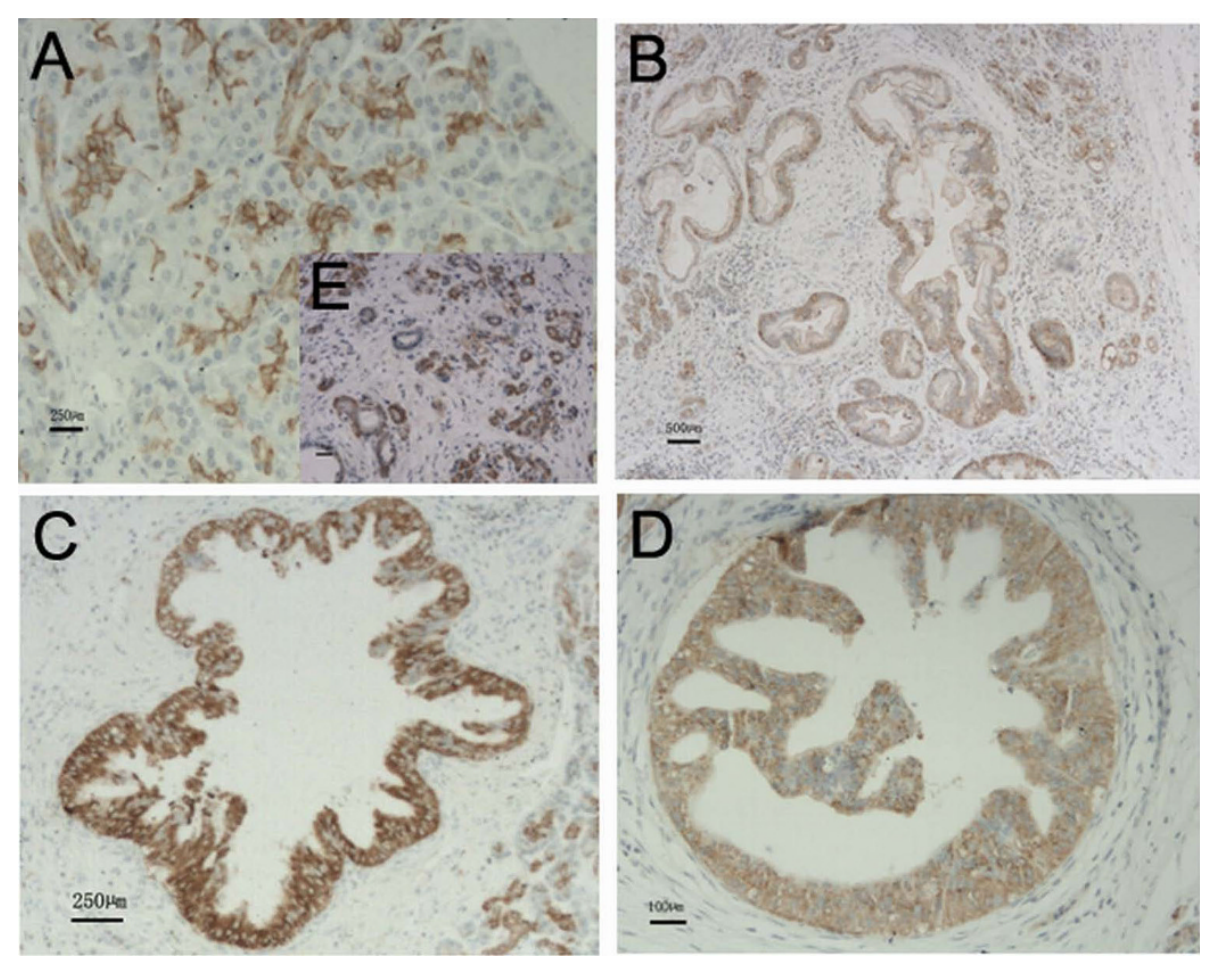

Figure 8 Expression of ezrin in intercalated duct cells, the tubular complexes of CP and PanINs. (A) Staining of ezrin in the intercalated duct cells in the paraneoplastic tissues. (B-D) Ezrin-positive staining in the representative clinical specimens of PanIN1, PanIN2 and PanIN3 ( $\times 100$ magnification). (E) Ezrin expression in the cells of the tubular complexes in CP ( $\times 100$ magnification).

participate in the early events of PDAC development and may promote its progression to the advanced stage.

\section{Acknowledgements}

This study was supported by the grant from the National Nature Science Foundation of China (No. 30471970), the grant from the National Science \& Technology Support Project of China grants(No. 2006BAl02A14) and the support from Roche Company. We thank Mr. M. Arpin (Institute Curie, Paris, France) for kindly providing the pcb6-ezrin construct.

\section{Authors' contributions}

YM participated in the design of the study, performed experiments, analyzed the data and drafted the manuscript. ZL performed the immunohistochemical evaluations and participated in writing the manuscript. SY contributed to study design and conducted the animal studies. QZ performed the experiments, analyzed the data and drafted the manuscript. YM contributed to data analysis. JC planned the study, supervised the statistical calculations, performed the immunohistochemical evaluations, coordinated the study and drafted the manuscript. All authors read and approved the final manuscript.

\section{Competing interests}

The authors declare that they have no competing interests.

Received: 10 February 2010 Accepted: 23 June 2010

Published: 23 June 2010

\section{References}

1. Sato N, Funayama N, Nagafuchi A, Yonemura S, Tsukita S, Tsukita S: A gene family consisting of ezrin, radixin and moesin. Its specific localization at actin filament/plasma membrane association sites. J Cell Sci 1992, 103(Pt 1):131-143.
2. Bretscher A, Edwards K, Fehon RG: ERM proteins and merlin: integrators at the cell cortex. Nat Rev Mol Cell Biol 2002, 3(8):586-599.

3. Pujuguet P, Del Maestro L, Gautreau A, Louvard D, Arpin M: Ezrin regulates E-cadherin-dependent adherens junction assembly through Rac1 activation. Mol Biol Cell 2003, 14(5):2181-2191.

4. Gautreau A, Louvard D, Arpin M: ERM proteins and NF2 tumor suppressor: the Yin and Yang of cortical actin organization and cell growth signaling. Curr Opin Cell Biol 2002, 14(1):104-109.

5. Mielgo A, Brondani V, Landmann L, Glaser-Ruhm A, Erb P, Stupack D, Günthert U: The CD44 standard/ezrin complex regulates Fas-mediated apoptosis in Jurkat cells. Apoptosis 2007, 12(11):2051-2061.

6. Hiscox S, Jiang WG: Ezrin regulates cell-cell and cell-matrix adhesion, a possible role with E-cadherin/beta-catenin. J Cell Sci 1999, 112(Pt 18):3081-3090.

7. Louvet-Vallée S: ERM proteins: from cellular architecture to cell signaling. Biol Cell 2000, 92(5):305-316.

8. Yonemura S, Hirao M, Doi Y, Takahashi N, Kondo T, Tsukita S, Tsukita S: Ezrin/radixin/moesin (ERM) proteins bind to a positively charged amino acid cluster in the juxta-membrane cytoplasmic domain of CD44, CD43, and ICAM-2. J Cell Biol 1998, 140(4):885-895.

9. Wu KL, Khan S, Lakhe-Reddy S, Jarad G, Mukherjee A, Obejero-Paz CA, Konieczkowski M, Sedor JR, Schelling JR: The NHE1 Na+/H+ exchanger recruits ezrin/radixin/moesin proteins to regulate Akt-dependent cell survival. J Biol Chem 2004, 279(25):26280-26286.

10. Yonemura S, Matsui T, Tsukita S, Tsukita S: Rho-dependent and -independent activation mechanisms of ezrin/radixin/moesin proteins: an essential role for polyphosphoinositides in vivo. J Cell Sci 2002, 115(Pt 12):2569-2580.

11. Gautreau A, Poullet P, Louvard D, Arpin M: Ezrin, a plasma membranemicrofilament linker, signals cell survival through the phosphatidylinositol 3-kinase/Akt pathway. Proc Natl Acad Sci USA 1999, 96(13):7300-7305. 
12. Fievet BT, Gautreau A, Roy C, Del Maestro L, Mangeat P, Louvard D, Arpin M: Phosphoinositide binding and phosphorylation act sequentially in the activation mechanism of ezrin. J Cell Biol 2004, 164(5):653-659.

13. Wick W, Grimmel C, Wild-Bode C, Platten M, Arpin M, Weller M: Ezrindependent promotion of glioma cell clonogenicity, motility, and invasion mediated by $\mathrm{BCL}-2$ and transforming growth factor-beta2. J Neurosci 2001, 21(10):3360-3368.

14. Crepaldi T, Gautreau A, Comoglio PM, Louvard D, Arpin M: Ezrin is an effector of hepatocyte growth factor-mediated migration and morphogenesis in epithelial cells. J Cell Biol 1997, 138(2):423-434.

15. Lugini L, Lozupone F, Matarrese P, Funaro C, Luciani F, Malorni W, Rivoltini L, Castelli C, Tinari A, Piris A, Parmiani G, Fais S: Potent phagocytic activity discriminates metastatic and primary human malignant melanomas: a key role of ezrin. Lab Invest 2003, 83(11):1555-1567.

16. Geiger KD, Stoldt P, Schlote W, Derouiche A: Ezrin immunoreactivity is associated with increasing malignancy of astrocytic tumors but is absent in oligodendrogliomas. Am J Pathol 2000, 157(6):1785-1793.

17. Yu Y, Khan J, Khanna C, Helman L, Meltzer PS, Merlino G: Expression profiling identifies the cytoskeletal organizer ezrin and the developmental homeoprotein Six-1 as key metastatic regulators. Nat Med 2004, 10(2):175-181.

18. Wei YC, Li CF, Yu SC, Chou FF, Fang FM, Eng HL, Uen YH, Tian YF, Wu JM, Li SH, Huang WW, Li WM, Huang HY: Ezrin overexpression in gastrointestinal stromal tumors: an independent adverse prognosticator associated with the non-gastric location. Mod Pathol 2009, 22(10):1351-60.

19. Khanna C, Khan J, Nguyen P, Prehn J, Caylor J, Yeung C, Trepel J, Meltzer P, Helman L: Metastasis-associated differences in gene expression in a murine model of osteosarcoma. Cancer Res 2001, 61(9):3750-3759.

20. Khanna C, Wan X, Bose S, Cassaday R, Olomu O, Mendoza A, Yeung C, Gorlick R, Hewitt SM, Helman LJ: The membrane-cytoskeleton linker ezrin is necessary for osteosarcoma metastasis. Nat Med 2004, 10(2):182-186.

21. Li Q, Wu M, Wang H, Xu G, Zhu T, Zhang Y, Liu P, Song A, Gang C, Han Z, Zhou J, Meng L, Lu Y, Wang S, Ma D: Ezrin silencing by small hairpin RNA reverses metastatic behaviors of human breast cancer cells. Cancer Lett 2008, 261(1):55-63.

22. Curto M, McClatchey Al: Ezrin...a metastatic detERMinant? Cancer Cell 2004, 5(2):113-114.

23. Yeh TS, Tseng JH, Liu NJ, Chen TC, Jan YY, Chen MF: Significance of cellular distribution of ezrin in pancreatic cystic neoplasms and ductal adenocarcinoma. Arch Surg 2005, 140(12):1184-1190.

24. Kitamura N, Iwamura T, Taniguchi S, Yamanari H, Kawano MA, Hollingsworth K, Setoguchi T: High collagenolytic activity in spontaneously highly metastatic variants derived from a human pancreatic cancer cell line (SUIT-2) in nude mice. Clin Exp Metastasis 2000, 18(7):561-571.

25. Hustinx SR, Fukushima N, Zahurak ML, Riall TS, Maitra A, Brosens L, Cameron JL, Yeo CJ, Offerhaus GJ, Hruban RH, Goggins M: Expression and prognostic significance of 14-3-3sigma and ERM family protein expression in periampullary neoplasms. Cancer Biol Ther 2005, 4(5):596-601.

26. Akisawa N, Nishimori I, Iwamura T, Onishi S, Hollingsworth MA: High levels of ezrin expressed by human pancreatic adenocarcinoma cell lines with high metastatic potential. Biochem Biophys Res Commun 1999, 258(2):395-400.

27. Cui Y, Li T, Zhang D, Han J: Expression of Ezrin and phosphorylated Ezrin (pEzrin) in pancreatic ductal adenocarcinoma. Cancer Invest 2010, 28(3):242-247.

28. Kocher HM, Sandle J, Mirza TA, Li NF, Hart IR: Ezrin interacts with cortactin to form podosomal rosettes in pancreatic cancer cells. Gut 2009, 58(2):271-284.

29. Barros JC, Marshall CJ: Activation of either ERK1/2 or ERK5 MAP kinase pathways can lead to disruption of the actin cytoskeleton. J Cell Sci 2005, 118(Pt 8):1663-1671.

30. Yip SC, El-Sibai M, Coniglio SJ, Mouneimne G, Eddy RJ, Drees BE, Neilsen PO, Goswami S, Symons M, Condeelis JS, Backer JM: The distinct roles of Ras and Rac in PI 3-kinase-dependent protrusion during EGFstimulated cell migration. J Cell Sci 2007, 120(Pt 17):3138-46.

31. Ling ZQ, Mukaisho $K$, Yamamoto $H$, Chen KH, Asano $S$, Araki $Y$, Sugihara $H$, Mao WM, Hattori T: Initiation of malignancy by duodenal contents reflux and the role of ezrin in developing esophageal squamous cell carcinoma. Cancer Sci 2010, 101(3):624-30.
32. Turunen $\mathrm{O}$, Wahlström $\mathrm{T}$, Vaheri $\mathrm{A}$ : Ezrin has a $\mathrm{COOH}$-terminal actinbinding site that is conserved in the ezrin protein family. J Cell Biol 1994, 126(6):1445-1453.

33. Andréoli $C$, Martin M, Le Borgne R, Reggio $H$, Mangeat $P$ : Ezrin has properties to self-associate at the plasma membrane. J Cell Sci 1994, 107(Pt 9):2509-2521.

34. Stylli SS, Kaye AH, Lock P: Invadopodia: at the cutting edge of tumour invasion. J Clin Neurosci 2008, 15(7):725-737.

35. Deryugina El, Bourdon MA, Reisfeld RA, Strongin A: Remodeling of collagen matrix by human tumor cells requires activation and cell surface association of matrix metalloproteinase-2. Cancer Res 1998, 58(16):3743-3750.

36. Park HR, Jung WW, Bacchini P, Bertoni F, Kim YW, Park YK: Ezrin in osteosarcoma: comparison between conventional high-grade and central low-grade osteosarcoma. Pathol Res Pract 2006, 202(7):509-515.

37. Elliott BE, Meens JA, SenGupta SK, Louvard D, Arpin M: The membrane cytoskeletal crosslinker ezrin is required for metastasis of breast carcinoma cells. Breast Cancer Res 2005, 7(3):R365-373.

38. Yeh CN, Pang ST, Chen TW, Wu RC, Weng WH, Chen MF: Expression of ezrin is associated with invasion and dedifferentiation of hepatitis $B$ related hepatocellular carcinoma. BMC Cancer 2009, 9:233.

39. Hruban $\mathrm{RH}$, Fukushima N: Pancreatic adenocarcinoma: update on the surgical pathology of carcinomas of ductal origin and PanINs. Mod Pathol 2007, , 20 Suppl 1: S61-70.

40. Zhang L, Sanderson SO, Lloyd RV, Smyrk TC: Pancreatic intraepithelial neoplasia in heterotopic pancreas: evidence for the progression model of pancreatic ductal adenocarcinoma. Am J Surg Pathol 2007, 31(8):1191-1195.

41. Rosty C, Geradts J, Sato N, Wilentz RE, Roberts H, Sohn T, Cameron JL, Yeo CJ, Hruban RH, Goggins M: p16 Inactivation in pancreatic intraepithelial neoplasias (PanINs) arising in patients with chronic pancreatitis. Am J Surg Pathol 2003, 27(12):1495-1501.

42. Ueda S, Fukamachi K, Matsuoka Y, Takasuka N, Takeshita F, Naito A, ligo M, Alexander DB, Moore MA, Saito I, Ochiya T, Tsuda H: Ductal origin of pancreatic adenocarcinomas induced by conditional activation of a human Ha-ras oncogene in rat pancreas. Carcinogenesis 2006, 27(12):2497-2510.

43. Wada R, Ogawa K, Yamaguchi T, Tanizaki T, Matsumoto M: Intercalated duct cell is starting point in development of pancreatic ductal carcinoma? J Carcinog 2005, 4:9.

44. Zhu L, Shi G, Schmidt CM, Hruban RH, Konieczny SF: Acinar cells contribute to the molecular heterogeneity of pancreatic intraepithelial neoplasia. Am J Pathol 2007, 171(1):263-273.

doi:10.1186/1479-5876-8-61

Cite this article as: Meng et al:: Ezrin promotes invasion and metastasis of pancreatic cancer cells. Journal of Translational Medicine 2010 8:61.

\section{Submit your next manuscript to BioMed Central and take full advantage of:}

- Convenient online submission

- Thorough peer review

- No space constraints or color figure charges

- Immediate publication on acceptance

- Inclusion in PubMed, CAS, Scopus and Google Scholar

- Research which is freely available for redistribution 